\title{
Expression of Variability in Corn as Influenced by Growth Stage Using Optical Sensor Measurements
}

\author{
K. L. Martin, K. Girma, K. W. Freeman, R. K. Teal, B. Tubańa, D. B. Arnall, B. Chung, O. Walsh, J. B. Solie, \\ M. L. Stone, and W. R. Raun*
}

\begin{abstract}
Improving crop management inputs with remote sensing devices is an emerging technology. This study documented the progression of the normalized difference vegetative index (NDVI) during the life cycle of corn (Zea mays $L_{\text {.) }}$, evaluated the spatial variability of corn growth in terms of the CV (calculated from NDVI readings), and documented the relationships between NDVI, $\mathrm{CV}$ (calculated from NDVI), and grain and biomass yields and plant density. Four rows, $30 \mathrm{~m}$ in length, from two locations during 2 yr were randomly selected for this study. An optical sensor was used to collect NDVI readings at multiple growth stages during the life cycle of corn. The NDVI increased with progression of vegetative growth stages until V10, where a plateau was encountered, followed by a decline in NDVI after the VT growth stage. Coefficient of variation data from the NDVI readings revealed two dominant peaks during the life cycle of corn, one between the V6 and V8 growth stages and the second during the late reproductive growth stages. The $\mathrm{CV}$ data illustrated that the greatest variation expressed by corn during the vegetative growth stages was between the $\mathrm{V} 6$ and $\mathrm{V8}$ growth stages. The highest correlation of NDVI with corn grain yield was found at the V7 to $V 9$ growth stages; likewise, $\mathrm{CV}$ and plant density were also more highly correlated from $\mathrm{V7}$ to $\mathrm{V} 9$. The $\mathrm{CV}$ from NDVI readings was highly correlated with grain and biomass yields at all growth stages.
\end{abstract}

$\mathrm{R}$ EMOTE SENSING TECHNOLOGY is increasing in popularity in agricultural settings. Today, there is a wide variety of uses for remote sensors and nearly all applications continue to undergo updates and revisions to improve their effectiveness. Along with the many sensors, there are also many different indices produced by these various sensors. For this study, our focus was on better understanding the NDVI in corn production. Vegetation indices such as NDVI have a direct relationship with crop canopy attributes such as biomass and grain yield (Ashcroft et al., 1990; Anderson and Hanson, 1992). Single wavelengths in the 510- to 760 -nm range or spectral vegetation indices such as the green simple ratio index (GSRI) and green normalized difference vegetative index (GNDVI) were proposed as predictors of corn grain yield (Elwadie et al., 2005). The normalized difference vegetative index is an index developed from two important wave bands: the red and near infrared. According to Knipling (1970) these two bands have unique

K.L. Martin, K. Girma, K.W. Freeman, R.K. Teal, B. Tubańa, D.B. Arnall, B. Chung, O. Walsh, and W.R. Raun, Dep. of Plant and Soil Sciences; and J.B. Solie and M.L. Stone, Dep. of Biosystems and Agricultural Engineering, Oklahoma State Univ., Stillwater, OK 74078. Contribution from the Oklahoma Agric. Exp. Stn. Mention of trademarked instruments does not imply endorsement. Received 22 Sept. 2005. *Corresponding author (wrr@mail.pss.okstate.edu).

Published in Agron. J. 99:384-389 (2007).

Remote Sensing

doi:10.2134/agronj2005.0268

(C) American Society of Agronomy

677 S. Segoe Rd., Madison, WI 53711 USA

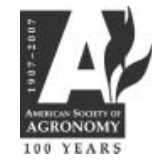

features. Reflected red radiation is known to negatively correlate with green leaf area, whereas reflected nearinfrared radiation is known to positively correlate with leaf area (Knipling, 1970). The index is given by

$$
\mathrm{NDVI}=\frac{\rho_{\mathrm{NIR}}-\rho_{\mathrm{Red}}}{\rho_{\mathrm{NIR}}+\rho_{\mathrm{Red}}}
$$

where $\rho_{\text {NIR }}$ is the fraction of emitted near infrared (NIR) radiation returned from the sensed area (reflectance) and $\rho_{\text {Red }}$ is the fraction of emitted red radiation returned from the sensed area (reflectance).

In a study designed to compare different vegetation indices as a means of assessing canopy variation and its impact on corn yield, Shanahan et al. (2001) showed that GNDVI values derived from images acquired during midgrain filling were the most highly correlated with grain yield. According to Gilbert et al. (1996), a significant logarithmic $\left(r^{2}=0.96, P<0.01\right)$ relationship was observed between NDVI and biomass where, after canopy closure, the biomass continued to increase after NDVI reached its maximum value. A study that compared $\mathrm{N}$ fertilizer recommendation based on NDVI and corn yield measurements showed that, at the V8 to V9 growth stage, the remotesensing-based $\mathrm{N}$ recommendation model was more accurate than models based on yield (Clay et al., 2006).

An additional benefit that sensor technology adds to production agriculture is the ability to quantitatively identify variability within a field. When considering the spatial resolution of photographic images, Simonett (1983) stated that spatial resolution may be defined as the minimum distance between two objects that a sensor can record distinctly. Independent of resolution or amount of variability, many studies have shown that variability has a negative impact on yield (Krall et al., 1977; Nielsen, 2001; Nafziger et al., 1991; Raun et al., 1986; Raun and Johnson, 1999).

The $\mathrm{CV}$ is a statistical parameter that can easily be used to calculate the variability in NDVI measurements taken across a given area. Freund and Wilson (2003) defined $\mathrm{CV}$ as the ratio of the standard deviation to the mean, expressed in percentage terms, or simply the standard deviation as a proportion of the mean. Washmon et al. (2002) used CV (calculated from Landsat satellite images) to evaluate variability in wheat (Triticum aestivum L.) and indicated that if within-field CVs could be predicted, yield estimations should improve.

This study documented the progression of NDVI and CV with time, which is similar to that found by Raun et al. (2005). The study conducted by Raun et al. (2005) took place in Texcoco, Mexico. The difference in climate, crop

Abbreviations: NDVI, normalized difference vegetative index; NIR, near infrared. 
Table 1. Planting date, harvest date, plant density, maturity, and grain moisture for each location (EFAW Experiment Station and Lake Carl Blackwell Experiment Station in Oklahoma) in 2003 and 2004.

\begin{tabular}{|c|c|c|c|c|c|}
\hline Location & $\begin{array}{c}\text { Planting } \\
\text { date }\end{array}$ & $\begin{array}{c}\text { Harvest } \\
\text { date }\end{array}$ & $\begin{array}{l}\text { Plant } \\
\text { density }\end{array}$ & Maturity & $\begin{array}{c}\text { Grain } \\
\text { moisture }\end{array}$ \\
\hline & & & $\begin{array}{l}\text { plants } \\
\text { ha }^{-1}\end{array}$ & d & $\%$ \\
\hline & \multicolumn{5}{|c|}{2003} \\
\hline EFAW & 31 Mar. 2003 & 5 Aug. 2003 & 51547 & 111 & 17 \\
\hline \multirow{2}{*}{$\begin{array}{l}\text { Lake Carl } \\
\text { Blackwell }\end{array}$} & 8 Apr. 2003 & 11 Aug. 2003 & 30940 & 108 & 15 \\
\hline & \multicolumn{5}{|c|}{2004} \\
\hline EFAW $\dagger$ & 7 Apr. 2004 & 25 Aug. 2004 & 68186 & 108 & 12 \\
\hline EFAW & 7 Apr. 2004 & 25 Aug. 2004 & 37029 & 108 & 12 \\
\hline $\begin{array}{l}\text { Lake Carl } \\
\text { Blackwell } \dagger\end{array}$ & 3 Apr. 2004 & 2 Aug. 2004 & 59656 & 108 & 18 \\
\hline $\begin{array}{l}\text { Lake Carl } \\
\text { Blackwell } \uparrow\end{array}$ & 3 Apr. 2004 & 2 Aug. 2004 & 36392 & 108 & 18 \\
\hline
\end{tabular}

$\dagger$ High plant density of Rows 1 and 2 at EFAW and Rows 1 and 2 at Lake Carl Blackwell.

Low plant density of Rows 3 and 4 at EFAW and Rows 3 and 4 at Lake Carl Blackwell.

growth period (April-August vs. July-December) and the fact that the study was conducted for only one growing season raised doubt as to whether a phenomenon or a common trend was observed. The data collected in Mexico, however, does follow the same trend as the data collected in this study (in the central USA). This study includes multiple-year data with the complete progression of NDVI and CV of NDVI throughout the complete life cycle of corn. Also, other treatments were avoided to keep from imposing unwanted effects on the outcome of NDVI and CV of NDVI.

The objectives of this study were to: (i) document the progression of NDVI during the life cycle of corn; (ii) evaluate the variability of corn growth in terms of $\mathrm{CV}$ during the life cycle of corn; and (iii) determine if relationships exist between NDVI, CV (calculated using NDVI), and grain and biomass yields and plant density.

\section{MATERIALS AND METHODS}

Two experimental sites were established in the spring of 2003, one at the Stillwater (EFAW) Research Station in Stillwater, $\mathrm{OK}$, on an Easpur loam (fine-loamy, mixed, superactive, thermic Fluventic Haplustoll) and one at the Lake Carl Blackwell Re- search Station west of Stillwater on a Pulaski fine sandy loam soil (coarse-loamy, mixed, nonacid, thermic Typic Ustifluvent). The production system used conventional tillage in a rainfed environment. Two Bacillus thuringiensis (bt) gene enhanced corn hybrids identified by their maturity (108 or $111 \mathrm{~d}$ ) were used in this study (planting dates, harvest dates, plant densities, maturities, and grain moisture are reported in Table 1).

Four rows, $30 \mathrm{~m}$ in length, were randomly identified at each location (from an area $>2 \mathrm{ha}$ ). Two rows at each location in 2004 were thinned to the density reported in Table 1 to evaluate differences due to plant density. Within each row, the cumulative distance of each plant from the beginning of each row was recorded at the V3 to V5 growth stage using a tape measure extended the length of the row. Plant locations were documented to evaluate relationships between collected data and plant density (computed using plant location measurements).

A GreenSeeker hand-held optical sensor (NTech Industries, Ukiah, CA) was used to record NDVI measurements at each growth stage (data accumulation started at the V3 growth stage at all locations and years except at Lake Carl Blackwell in 2003, which began at the V6 growth stage) during the course of this study (growth stages at which data were accumulated are reported in Table 2). Each growth stage was identified using the classification terms developed by Iowa State University (1993). The sensor unit was manually carried with the data collection region of the sensor (sensor head) in the nadir position $0.8 \mathrm{~m}$ directly above the corn canopy. The sensor was carried at a relatively constant pace the length of each (30-m) row to collect approximately 600 readings per row.

The mean NDVI and CV of NDVI were calculated for each row at each respective growth stage. At physiological maturity, the aboveground biomass was hand harvested and calculated for each plant, then averaged for the entire row (harvest dates are reported in Table 1). The ears were removed from each plant and dried in a forced-air oven at $75^{\circ} \mathrm{C}$ for $4 \mathrm{~d}$, at which time the weights were recorded. The kernels were removed from the ears and reported as grain yield. The corn grain and plant biomass yields reported in Table 3 were calculated for each row and averaged for each location. Correlation of grain yield, biomass yield, and plant density with NDVI and CV of NDVI was determined using the correlation procedure in SAS (SAS Institute, 2002).

\section{RESULTS AND DISCUSSION Normalized Difference Vegetative Index with Time}

The NDVI readings that were collected throughout the life cycle of corn followed the expected trend of

Table 2. Coefficients of determination $\left(R^{2}\right)$ of grain yield, biomass yield (reported in Table 3), and plant density with normalized difference vegetative index (NDVI) and CV of NDVI measurements for each growth stage from V3 to VT, combined over four separate rows, $30 \mathrm{~m}$ in length, at the EFAW Experiment Station and the Lake Carl Blackwell Experiment Station in 2003 and 2004.

\begin{tabular}{|c|c|c|c|c|c|c|c|c|c|c|}
\hline \multirow[b]{2}{*}{ Parameter } & \multicolumn{10}{|c|}{ Growth stage } \\
\hline & $\mathbf{V 3}$ & V4 & V5 & V6 & V7 & v8 & V9 & V10 & V12 & $\mathbf{V T}$ \\
\hline & \multicolumn{10}{|c|}{ NDVI } \\
\hline Grain yield & $0.12 \mathrm{NS}$ & $0.00 \mathrm{NS}$ & $0.05 \mathrm{NS}$ & $0.29 *$ & $0.26 *$ & $0.66^{* * *}$ & $0.61 * *$ & $0.56^{* *}$ & $0.64 * *$ & $0.40^{*}$ \\
\hline Biomass yield & $0.02 N S$ & 0.00NS & $0.00 \mathrm{NS}$ & $0.20 \dagger$ & $0.19 \dagger$ & $0.66^{* * *}$ & $0.64 * *$ & $\mathbf{0 . 6 1} 1^{* *}$ & $0.59 * *$ & $0.42 *$ \\
\hline \multirow[t]{2}{*}{ Plant density } & 0.03NS & 0.02NS & 0.01NS & $0.30 *$ & $0.34 *$ & $0.66 * *+$ & $\mathbf{0 . 7 2} * *+$ & $0.59 * *+$ & $0.27 *$ & $0.12 N S$ \\
\hline & \multicolumn{10}{|c|}{ CV, \% } \\
\hline Grain yield & $0.66 *+$ & $0.69 * *+$ & $0.66 *$ & $0.74 * *$ & $0.52 *+$ & $0.62 * *+$ & $0.69^{* *+}$ & $0.67 * *+$ & $0.72 * *+$ & $0.66 * *+$ \\
\hline Biomass yield & $0.61 *$ & $0.76 * *$ & $0.77 * *$ & $\mathbf{0 . 7 4} * *$ & $0.62 * *+$ & $0.66 * * \cdots$ & $0.72 * *$ & $0.69 * *$ & $\mathbf{0 . 7 9} * *+$ & $\mathbf{0 . 6 9} * *+$ \\
\hline Plant density & $0.74 * * \div$ & $0.77 * *$ & $0.59 * \div$ & $0.72^{* *+}$ & $0.86 * *$ & $0.90 * * \div$ & $0.85^{* * *}$ & $0.56 * *+$ & $0.49 *$ & $0.36^{* \ddagger}$ \\
\hline
\end{tabular}

* Significant at the 0.05 level. NS, not significant.

*** Significant at the 0.01 level.

$\dagger$ Significant at the 0.10 level.

+ Relationships with negative slopes. 
Table 3. Corn grain yield and plant biomass yield for each row (mean of individual plant yields) and averaged for each location (EFAW Experiment Station and Lake Carl Blackwell [LCB] Experiment Station) in 2003 and 2004.

\begin{tabular}{|c|c|c|c|}
\hline \multirow[b]{3}{*}{ EFAW 2003} & \multirow[t]{2}{*}{ Row } & Mean corn grain & Mean biomass \\
\hline & & \multicolumn{2}{|c|}{$\mathrm{kg} \mathrm{ha}^{-1}$} \\
\hline & 1 & 6480 & 12409 \\
\hline EFAW 2003 & 2 & 6231 & 12503 \\
\hline EFAW 2003 & 3 & 6589 & 13030 \\
\hline \multirow[t]{2}{*}{ EFAW 2003} & 4 & 6954 & 13892 \\
\hline & mean & 6564 & 12959 \\
\hline LCB 2003 & 1 & 4224 & 6891 \\
\hline LCB 2003 & 2 & 5233 & 8010 \\
\hline LCB 2003 & 3 & 3449 & 11180 \\
\hline \multirow{2}{*}{ LCB 2003} & 4 & 4539 & 6189 \\
\hline & mean & 4361 & 8068 \\
\hline EFAW 2004 $\dagger$ & 1 & 8759 & 15038 \\
\hline \multirow[t]{2}{*}{ EFAW 2004 $\dagger$} & 2 & 8943 & 15166 \\
\hline & mean & 8551 & 15102 \\
\hline EFAW 2004 & 3 & 6223 & 11836 \\
\hline \multirow{2}{*}{ EFAW 2004 } & 4 & 5806 & 11091 \\
\hline & mean & 6015 & 11463 \\
\hline LCB 2004 & 1 & 5783 & 12171 \\
\hline \multirow[t]{2}{*}{ LCB $2004 \dagger$} & 2 & 5848 & 11013 \\
\hline & mean & 5815 & 11592 \\
\hline LCB 2004\% & 3 & 4855 & 8408 \\
\hline \multirow[t]{2}{*}{ LCB 2004 } & 4 & 4094 & 7674 \\
\hline & mean & 4474 & 8041 \\
\hline
\end{tabular}

$\dagger$ Normal plant density of Rows 1 and 2 at EFAW and Rows 1 and 2 at Lake Carl Blackwell.

Low plant density of Rows 3 and 4 at EFAW and Rows 3 and 4 at Lake Carl Blackwell.

vegetation coverage with time. As corn plants emerged, biomass per unit land area was small, and NDVI values were low (Fig. 1-4). The average NDVI of all rows

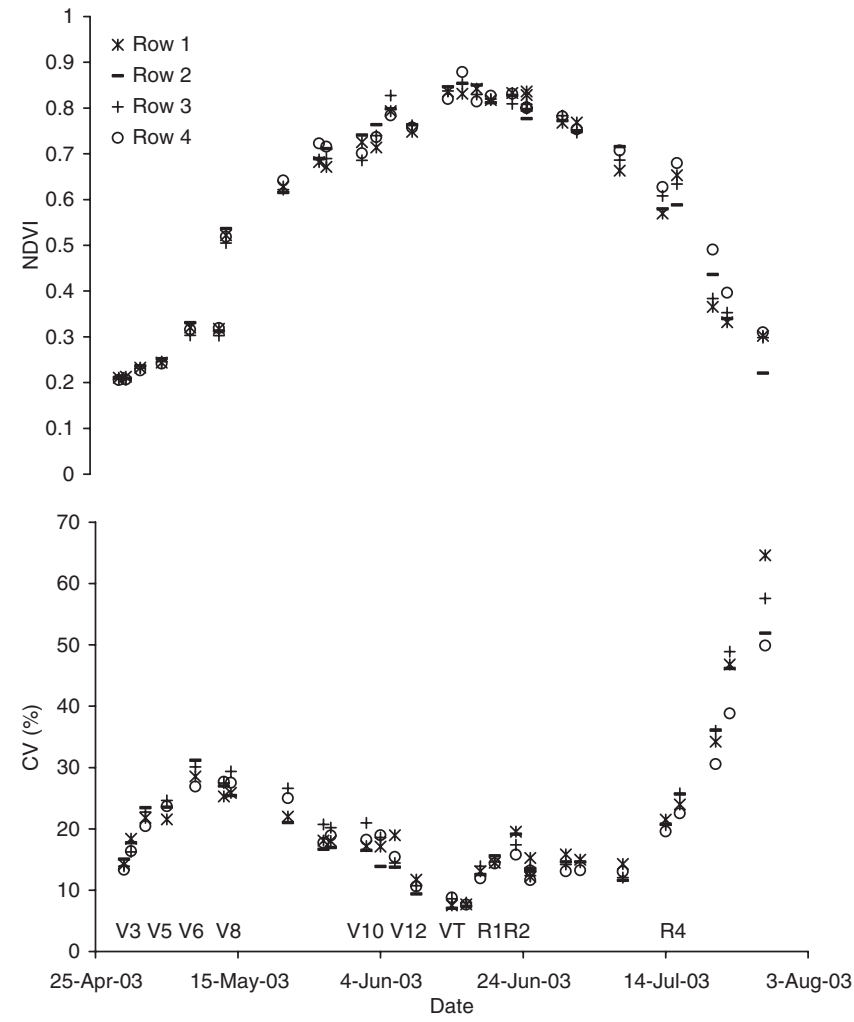

Fig. 1. Mean normalized difference vegetative index (NDVI) and CV from NDVI readings determined from four separate rows, $30 \mathrm{~m}$ in length, during growth stages ranging from V3 to R5, EFAW Experiment Station, 2003.

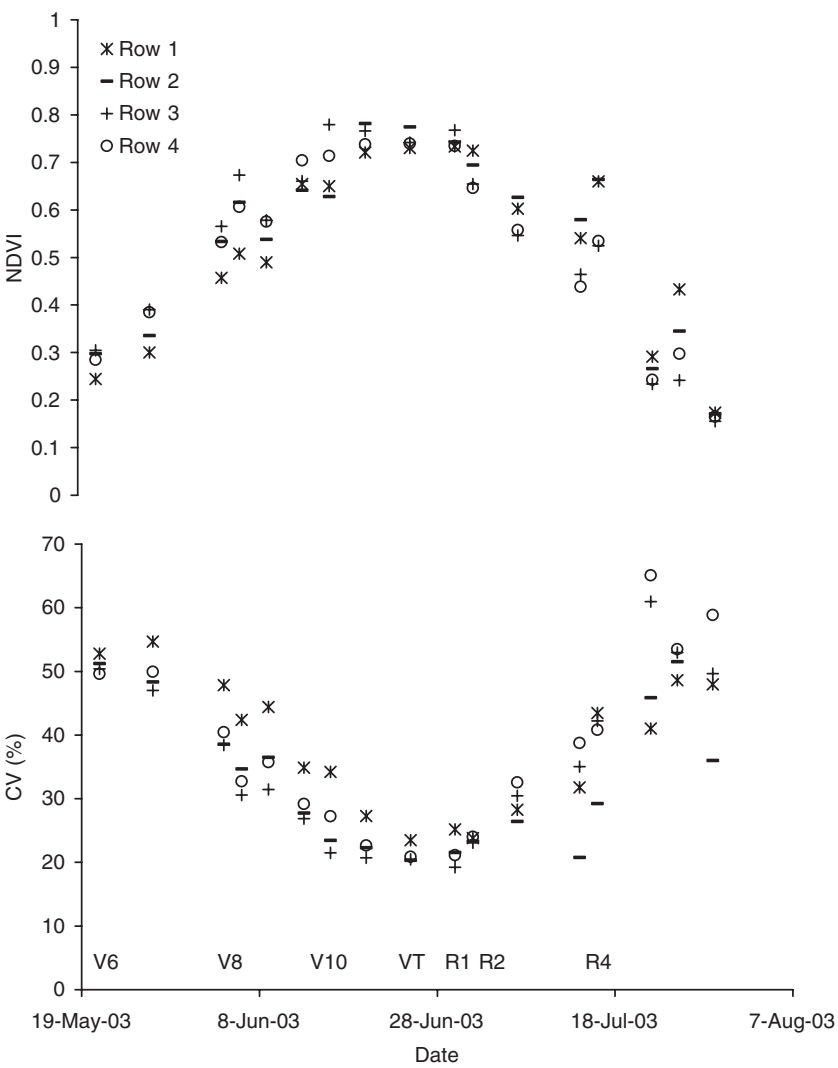

Fig. 2. Mean normalized difference vegetative index (NDVI) and CV from NDVI readings determined from four separate rows, $30 \mathrm{~m}$ in length, during growth stages ranging from V6 to R5, Lake Carl Blackwell Experiment Station, 2003.

at all sites during vegetative growth was lowest at the V3 growth stage because soil reflectance dominated the NDVI measurement. As plants grew and developed, however, NDVI rapidly increased (between growth stages V3 and V10) as the canopy covered the soil with overlapping leaves (Fig. 1-4). During these stages, it was apparent that NDVI was proportional to the level of vegetation coverage.

There were only small changes in the NDVI values between the V10 growth stage and the VT growth stage, reaching a maximum value at or just before tasseling. At the point of canopy closure, the sensor was almost exclusively measuring plant material. Therefore, the data acquired after canopy closure involved almost no red reflectance, so changes in NDVI thereafter relied on NIR differences. When tassels were fully emerged, NDVI decreased due to the yellowing of mature tassels. As plants entered the reproductive stages and senescence occurred on the lower portions of the plant, NDVI decreased more rapidly. As senescence moved to the top of the plant, NDVI was depressed as low as 0.30 .

Differences in NDVI across locations were encountered in both years of this study. These differences are due to natural differences in soil type, texture, water holding capacities, and differences in timely rainfall that ultimately influenced the growth of the corn. During the tassel period, abnormal deviations in NDVI (usually lower values) were probably due to the low quantity of chlorophyll present in the tassel. 


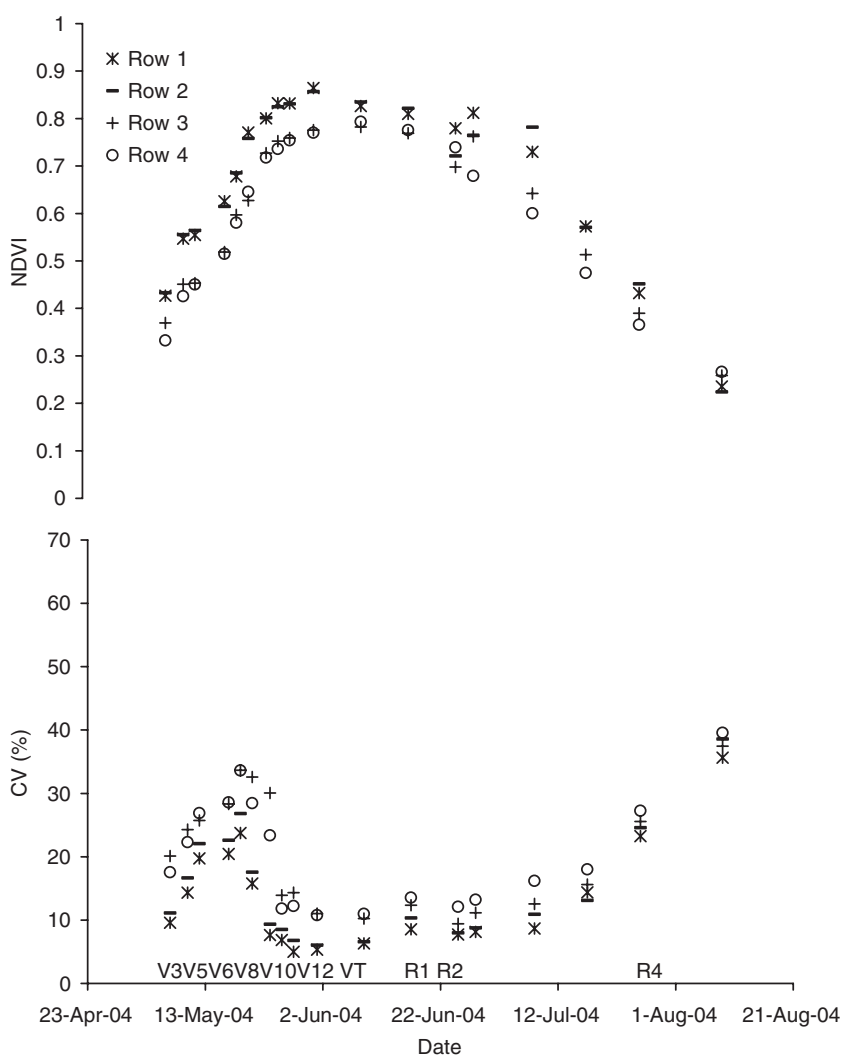

Fig. 3. Mean normalized difference vegetative index (NDVI) and CV from NDVI readings determined from four separate rows, $30 \mathrm{~m}$ in length, during growth stages ranging from V3 to R5, EFAW Experiment Station, 2004.

\section{Coefficient of Variation with Time}

Figures 1 to 4 show the data for each specific site for both years. During the early growth stages (V3-V4), the NDVI data were generated from the soil surface and a very small portion of plant material. Therefore, CVs (calculated from NDVI) for each row were low. Coefficient of variation values reached a maximum between the V6 and V8 growth stages (Fig. 1, 3, and 4). At this peak, the plants did not accumulate enough vegetation to cover the within-row soil surface, and expressed the greatest amount of variability. After one to two additional growth stages, a rapid decline in variability followed at all sites (Fig. 1-4).

The CVs reached a minimum value at or just before the VT growth stage, followed by another rapid increase in CV (Fig. 1-4). These growth stages (V12-VT) correspond to the time at which the NDVI values reached their highest point, as illustrated in Fig. 1 to 4 . As a visual determination, the corn at the V10 to V12 growth stage appeared to be at the most uniform stage, as differences were very difficult to recognize. Likewise, the $\mathrm{CV}$ data generated with time reached its lowest value just before tasseling, when complete canopy coverage and leaf overlap created the most homogeneity encountered in the growing season. Immediately after tasseling, the small peak in CV values expressed in some years (e.g., EFAW 2003) was probably due to the full expression of the tassels and the uneven tassel emergence (Fig. 1).
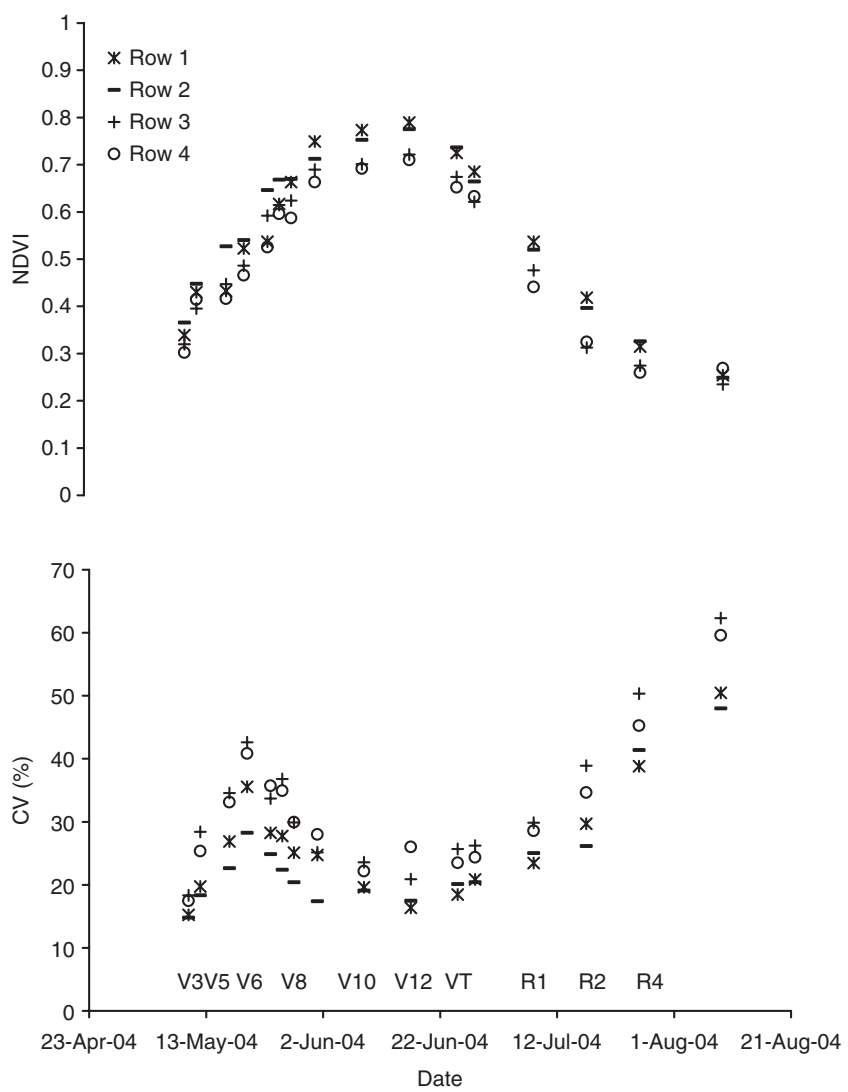

Fig. 4. Mean normalized difference vegetative index (NDVI) and CV from NDVI readings determined from four separate rows, $30 \mathrm{~m}$ in length, during growth stages ranging from V3 to R5, Lake Carl Blackwell Experiment Station, 2004.

This small peak carried over into the early reproductive growth stages (R1-R2) at the EFAW location.

After the reproductive stages (R2-R5), the expressed $\mathrm{CV}$ of the NDVI values increased and as a result, the highest CVs were found at these growth stages. As senescence occurred, the sensor measured NDVI from leaves containing a wide range of green and non-green color intensities. The highest CVs were found as the plants approached full maturity, when the senescence neared the top of the plant and the lighter color had a greater impact on NDVI values.

Some differences can be noted in the 2004 growing season due to differences in plant density. The purpose of implementing variation in plant density was to more fully understand how the density affects the $\mathrm{CV}$ with time. In Fig. 3 and 4 , there is a trend for the lower density to display elevated CVs. Although the CVs increased in the lower density, the trend for the $\mathrm{CV}$ with time remained the same; more specifically, the vegetative growth stage at which a peak was observed did not change. Other differences in $\mathrm{CV}$ observed at other locations (similar to NDVI) were probably due to soil differences or water availability changes.

\section{Corn Grain and Plant Biomass Yields}

At the early growth stages (V3-V5), both grain and biomass yields were poorly correlated with NDVI $\left(R^{2}<\right.$ 
$0.12, P>0.26)$, but increased between the V6 and V7 growth stages $\left(R^{2}<0.29, P>0.03\right)$ and was the highest from the V8 to the V12 growth stage. Between the V8 and V12 growth stages, the correlation of NDVI with grain and biomass yields were at $P<0.008$ and $R^{2}=$ 0.56 to 0.66 for grain yields and $P<0.006$ and $R^{2}=0.59$ to 0.66 for biomass yields. The highest relationship for any one growth stage was found at V8 for both grain and biomass yields $\left(R^{2}=0.66\right.$; Table 2$)$.

Since NDVI was highly correlated with grain and biomass yields at the V8 growth stage (for the locations and years of this study), the V8 growth stage is probably the most appropriate stage to evaluate corn for potential grain yield and biomass estimation. At all locations, the expressed variability was greatest at the V6 to V8 growth stage (high CV) compared with the later growth stages.

\section{Plant Density}

Arnall (2004) used an optical sensor to evaluate the relationship of CV of NDVI readings to plant density in wheat. He found that CV increased as plant density decreased and established a critical CV using a linear plateau model. He concluded that adding an estimate of plant density to yield prediction models can improve the model. This study showed that the CV of NDVI measurements and NDVI alone were related to plant density (Table 2). The stage with the highest correlation of CV to plant density was between V7 to V9 $\left(R^{2}>0.85, P<\right.$ 0.0001 , negative relationship; Table 2). At the earlier growth stages (V3-V6), the correlation was between 0.59 and 0.77 (inversely related). After the V9 growth stage, the $R^{2}$ decreased from 0.85 to 0.56 (negative relationship) at V10 and continued to decrease thereafter. At the V6 to V12 growth stages, NDVI was related to plant density $\left(R^{2}=0.30-0.72, P<0.05\right)$, but no statistically significant correlation was found before the V6 or VT growth stages.

Based on these results, plant density can be estimated in corn via CV generated from NDVI readings. The relationship decreased dramatically as canopy closure occurred (V10 growth stage), thus suggesting that sensor technology application for assessment of plant density should occur before the V10 growth stage.

Determining the variability within each fixed area via CV generated from remote sensors could be very important. In corn, CV (calculated from NDVI) could allow the estimation of plant density, thus revealing the areas where plants are too sparse to reach the yield potential of other areas with a greater plant density. To illustrate this, Table 3 clearly shows that the low densities in 2004 did not achieve the same yield as the higher densities. Here, the only difference between Rows 1 and 2 and Rows 3 and 4 was the density $(P<0.05)$, creating a reduction in mean grain yield of 2536 and $1341 \mathrm{~kg} \mathrm{ha}^{-1}$ at EFAW and Lake Carl Blackwell, respectively.

Plant density was related to grain yield $\left(R^{2}=0.64, P<\right.$ $0.0002)$ and biomass yield $\left(R^{2}=0.71, P<0.0001\right)$. Again, this illustrates the positive relationship between plant density and yield (both grain and biomass). It should be noted that although relationships exist between plant density and yield, both yield and plant density could be influenced by other factors included in this experiment. It could also be inferred from the relationships described here that the CV of NDVI readings and the yield of both grain and biomass would be related, which was an additional result of this study. Grain and biomass yields were related to CV at $R^{2}>0.52$ and $P<0.05$ (containing a negative slope) for a wide range of vegetative growth stages (V3-VT; Table 2), thus showing that the yield decreases as the variability in the corn increases.

\section{CONCLUSIONS}

Corn grain and plant biomass yields were found to have the highest correlation with NDVI from the V8 to V12 growth stages, which is similar to other studies. Plant density was highly correlated with the CV from NDVI readings at the V7 to V9 growth stages and decreased at V10. Also, corn grain and biomass yields were correlated with plant density and negatively correlated with CV. Therefore, the CV of NDVI measurements should be able to improve yield potential estimation above that of NDVI alone. The CV could be used to assess the influence of plant spacing on yield or could be used to identify a threshold $\mathrm{CV}$ in corn similar to that of Arnall (2004).

Little work has been done using $\mathrm{CV}$ as a predictor for grain yield. By using CV as an indicator of the magnitude of variability within a field, it could become important. Additional research is required, however, to confirm this and the proper scale at which CV should be used.

By combining the results found from NDVI generated with time, $\mathrm{CV}$ with time, yield, and plant spacing, the optimum growth stage at which remote sensors could be used can be deciphered for the various uses of remote sensors.

\section{REFERENCES}

Anderson, G.L., and J.D. Hanson. 1992. Evaluating handheld radiometer derived vegetation indices for estimating above ground biomass. Geocarto Int. 1:71-78.

Arnall, D.B. 2004. Relationship between coefficient of variation measured by spectral reflectance and plant density at early growth stages in winter wheat. M.S. thesis. Oklahoma State Univ., Stillwater, OK.

Ashcroft, P.M., J.A. Catt, P.J. Curran, J. Munden, and R. Webster. 1990. The relation between reflected radiation and yield on the Broadbaik winter wheat experiment. Int. J. Remote Sens. 11:1821-1836.

Clay, D.E., K.-I. Kim, J. Chang, S.A. Clay, and K. Dalsted. 2006. Characterizing water and nitrogen stress in corn using remote sensing. Agron. J. 98:579-587.

Elwadie, M.E., F.J. Pierce, and J. Qi. 2005. Remote sensing of canopy dynamics and biophysical variables estimation of corn in Michigan. Agron. J. 97:99-105.

Freund, R.J., and W.J. Wilson. 2003. Statistical methods. 2nd ed. Academic Press, San Diego.

Gilbert, M.A., S. Gandia, and J. Meliá. 1996. Analyses of spectralbiophysical relationships for a corn canopy. Remote Sens. Environ. 55:11-20.

Iowa State University. 1993. How a corn plant develops. Spec. Rep. 48. Available at http://maize.agron.iastate.edu/corngrows.html\#v9mg (accessed March 2005; verified 27 Sept. 2006). Iowa State Univ. Coop. Ext. Service, Ames.

Knipling, E.B. 1970. Physical and physiological basis for the reflectance of visible and near-infrared radiation from vegetation. Remote Sens. Environ. 1:155-159. 
Krall, J.M., H.A. Esechie, R.J. Raney, S. Clark, G. TenEyck, M. Lundquest, N.E. Humburg, L.S. Axthelm, A.D. Dayton, and R.L. Vanderlip. 1977. Influence of within-row variability in plant spacing on corn grain yield. Agron. J. 69:797-799.

Nafziger, E.D., P.R. Carter, and E.E. Grahm. 1991. Response of corn to uneven emergence. Crop Sci. 31:811-815.

Nielsen, R.L. 2001. Stand establishment variability in corn. Publ. AGRY-91-01. Dep. of Agronomy, Purdue Univ., West Lafayette, IN.

Raun, W.R., and G.V. Johnson. 1999. Improving nitrogen use efficiency for cereal production. Agron. J. 91:357-363.

Raun, W.R., D.H. Sander, and R.A. Olson. 1986. Emergence of corn as affected by source and rate of fertilizers applied with the seed. J. Fert. Issues 3:18-24.

Raun, W.R., J.B. Solie, K.L. Martin, K.W. Freeman, M.L. Stone, G.V. Johnson, and R.W. Mullen. 2005. Growth stage, development, and spatial variability in corn evaluated using optical sensor readings. J. Plant Nutr. 28:173-182.

SAS Institute. 2002. The SAS system for Windows, version 8.02. SAS Inst., Cary, NC.

Shanahan, J.F., J.S. Schepers, D.D. Francis, G.E. Varvel, W.W. Wilhelm, J.M. Tringe, M.R. Schlemmer, and D.J. Major. 2001. Use of remote-sensing imagery to estimate corn grain yield. Agron. J. 93:583-589.

Simonett, D.S. 1983. The development and principles of remote sensing. p. 1-35. In D.S. Simonett (ed.) Manual of remote sensing. 2nd ed. Vol. 1. Theory, instruments and techniques. Am. Soc. Photogramm., Falls Church, VA.

Washmon, C.N., J.B. Solie, W.R. Raun, and D.D. Itenfisu. 2002. Within field variability in wheat grain yields over nine years in Oklahoma. J. Plant Nutr. 25:2655-2662. 